\title{
Developmental myosins: expression patterns and functional significance
}

\author{
Stefano Schiaffino ${ }^{1 *}$, Alberto C. Rossi ${ }^{2}$, Vika Smerdu ${ }^{3}$, Leslie A. Leinwand ${ }^{2}$ and Carlo Reggiani ${ }^{4,5}$
}

\begin{abstract}
Developing skeletal muscles express unique myosin isoforms, including embryonic and neonatal myosin heavy chains, coded by the myosin heavy chain 3 (MYH3) and MYH8 genes, respectively, and myosin light chain 1 embryonic/atrial, encoded by the myosin light chain 4 (MYL4) gene. These myosin isoforms are transiently expressed during embryonic and fetal development and disappear shortly after birth when adult fast and slow myosins become prevalent. However, developmental myosins persist throughout adult stages in specialized muscles, such as the extraocular and jaw-closing muscles, and in the intrafusal fibers of the muscle spindles. These myosins are re-expressed during muscle regeneration and provide a specific marker of regenerating fibers in the pathologic skeletal muscle. Mutations in MYH3 or MYH8 are responsible for distal arthrogryposis syndromes, characterized by congenital joint contractures and orofacial dysmorphisms, supporting the importance of muscle contractile activity and body movements in joint development and in shaping the form of the face during fetal development. The biochemical and biophysical properties of developmental myosins have only partially been defined, and their functional significance is not yet clear. One possibility is that these myosins are specialized in contracting against low loads, and thus, they may be adapted to the prenatal environment, when fetal muscles contract against a very low load compared to postnatal muscles.
\end{abstract}

Keywords: Muscle development, Muscle regeneration, Myosin heavy chain, Embryonic myosin, Neonatal myosin, Distal arthrogryposis

\section{Review}

Introduction

Sarcomeric myosins present in mammalian striated muscle are class II or conventional myosins, each myosin molecule consisting of two heavy chains (MyHCs), two essential light chains (MLCs), and two regulatory MLCs. Both MyHCs and MLCs are present in different isoforms encoded by different genes. A total of 11 MyHCs is coded by 6 myosin heavy chain $(M Y H)$ genes which are widely expressed in body muscles and 5 other genes with limited expression in specialized skeletal muscles. Five essential MLCs are coded by four myosin light chain $(M Y L)$ genes, and two regulatory MLCs by two other MYL genes (Table 1) (see [1]). Most of these genes are also expressed in the developing skeletal muscle, including two MyHC isoforms, called embryonic

\footnotetext{
* Correspondence: stefano.schiaffino@unipd.it

${ }^{1}$ Venetian Institute of Molecular Medicine (VIMM), Via G. Orus 2, 35129

Padova, Italy

Full list of author information is available at the end of the article
}

and neonatal (or perinatal) myosins, coded by $M Y H 3$ and $M Y H 8$, respectively, and myosin light chain 1 embryonic/atrial, coded by the MYL4 gene, which are present at high levels in the initial stages of muscle development, are downregulated after birth, and are reexpressed during muscle regeneration. Here, we review the pattern of expression of myosin genes during muscle development, focusing especially on embryonic and neonatal MyHCs. In addition, we discuss the human pathologies due to mutation of $M Y H 3$ and $M Y H 8$ and the unsettled question of the functional significance of these myosins.

\section{Identification of developmental myosins in mammalian skeletal muscle}

A number of studies in the 1960s and 1970s reported biochemical evidence suggesting that myosins isolated from mammalian embryonic or fetal skeletal muscle differ from adult muscle myosins (see references in $[2,3])$. However, Whalen et al. [2] were the first to 
Table 1 MYH and MYL genes expressed in developing mammalian skeletal muscle

\begin{tabular}{|c|c|c|c|}
\hline Protein & Gene & Expression in developing muscle & Expression in adult muscle \\
\hline \multicolumn{4}{|c|}{ Myosin heavy chains $^{a}$} \\
\hline MyHC-emb & MYH3 & Embryonic and fetal muscle & Specialized muscles ${ }^{b}$ \\
\hline MyHC-neo & MYH8 & Embryonic and fetal muscle & Specialized muscles ${ }^{b}$ \\
\hline MyHC-slow & MYH7 & Embryonic and fetal muscle & Type 1 muscle fibers and ventricles \\
\hline $\mathrm{MyHC}-2 \mathrm{~A}$ & MYH2 & Fetal (human) or early postnatal (mouse) muscle & Type $2 \mathrm{~A}$ muscle fibers \\
\hline $\mathrm{MyHC}-2 \mathrm{X}$ & MYH1 & Late fetal (human) or early postnatal (mouse) muscle & Type $2 X$ muscle fibers \\
\hline MyHC-2B & MYH4 & Postnatal muscle & Type 2B muscle fibers \\
\hline \multicolumn{4}{|c|}{ Essential myosin light chains ${ }^{c}$} \\
\hline MLC-1 fast ${ }^{d}$ & MYL1 & Embryonic muscle & Fast muscle \\
\hline$M L C-3 f_{a s t}{ }^{d}$ & MYL1 & Fetal muscle (mouse: after E15) & Fast muscle $(2 \mathrm{~B}>2 \mathrm{~A})$ \\
\hline MLC-1emb/atrial & MYL4 & Embryonic muscle, heart & Atria \\
\hline MLC-1sb & MYL3 & Fetal muscle (mouse: after E15) & Slow skeletal muscle and ventricles \\
\hline MLC1-sa & MYL6B & Fetal muscle (human) & $\begin{array}{l}\text { Slow skeletal muscle, not ventricles, } \\
\text { in human, not mouse }\end{array}$ \\
\hline \multicolumn{4}{|c|}{ Regulatory myosin light chains } \\
\hline MLC-2fast & MYLPF & Embryonic and fetal muscle & Fast muscle \\
\hline MLC-2slow & MYL2 & Embryonic and fetal muscle & Slow muscle and ventricles \\
\hline
\end{tabular}

${ }^{2}$ Other five MyHCs coded by genes with limited expression in specialized skeletal muscles (MYH6, MYH7b, MYH13, MYH15, and MYH16) are not considered in this Table (see [1])

${ }^{\mathrm{b}}$ Extraocular, masticatory, laryngeal muscles, and muscle spindles

'An additional MLC, coded by the MYL6 gene, which is normally expressed in smooth muscle and non-muscle cells, is detectable in human fetal muscle and human cultured muscle cells [50]. However, it is not clear whether this MLC is associated to sarcomeric myosins

${ }^{\mathrm{d}}$ Splicing product of the MYL1 gene

provide unambiguous evidence for the existence of distinct developmental myosins. They identified two specific MyHCs, called embryonic and neonatal (also called perinatal) MyHCs, hereafter referred to as MyHC-emb and MyHC-neo, which precede the appearance of adult fast myosins in the developing rat skeletal muscle [2]. The corresponding $M Y H$ genes were identified [4, 5] and found to be located in the same chromosomal locus as gene coding for adult fast myosin heavy chains on chromosome 11 (mouse) or 17 (human) [6]. The gene coding for MyHCneo (MYH8) shows considerable sequence similarity with adult fast $M Y H$ genes, whereas the gene coding for MyHC-emb (MYH3) is quite different (see [7] for a comparative sequence analysis of $M Y H$ genes). Embryonic skeletal muscles also contain a unique type of essential MLC, MLC-1emb, encoded by the MYL4 gene, which is also expressed in the developing heart and in adult atrial myocardium but not in adult skeletal muscle $[8,9]$.

\section{Developmental myosins in other vertebrates}

Developmental myosins are also present in other vertebrates, such as birds and fish, although the sarcomeric myosin gene families are still incompletely characterized in these species. The identification of developmental myosins in fish is complicated by the large number of myosin genes, resulting from whole-genome duplication [10]. In the zebrafish embryo, diversification of fast and slow muscle cell lineages occurs very early in development, under the control of specific signaling pathways, leading to regional specification of different fast and slow MyHC isoforms. Three slow-type myosin genes, smyhc1, smyhc2, and smyhc3, that form a tandem array in the genome, show differential expression patterns, with primary slow fibers predominantly expressing smyhc1 and secondary slow fibers, which are formed later in development, expressing smyhc2 and smyhc3 [11]. Six fast-type myosin genes, arranged as triple repeats located in a narrow region on opposite strands of chromosome 5, also display distinct expression patterns in the zebrafish embryo: the genes in group 1 (fmyhc1.1, fmyhc1.2, and fmyhc1.3) are excluded from the tail and the majority of the cranial muscle, whereas the genes in group 2 (fmyhc2.1, fmyhc2.2, and $f m y h c 2.3$ ) are highly expressed in the cranial muscles [12].

In birds, three embryonic and one neonatal $\mathrm{MyHC}$ have been identified in developing skeletal muscles (reviewed by [13]). In addition, the myotome and the developing muscles in chick embryo contain three slowtype MyHCs, referred to as SM1 (or MyHC1), SM2 (or MyHC2), and SM3 (or MyHC3), SM3 being also expressed in the atrial myocardium [13, 14]. Ventricular $\mathrm{MyHC}$ is also transiently expressed in the embryonic chick skeletal muscles and is re-expressed during muscle regeneration [14]. The expression of slow-type MyHCs 
occurs in specific skeletal muscles independently of innervation, as a result of the existence of distinct lineages of myogenic precursors (see [15]). The switching from developmental to adult isoforms also varies in different chicken muscles: a complete switch from embryonic/ neonatal-to-adult fast $\mathrm{MyHC}$ occurs in the pectoralis muscle, but most other muscles contain embryonic/neonatal isoforms as major components throughout adult stages [13].

\section{Embryonic and neonatal myosins during rat and mouse muscle development}

Embryonic and neonatal myosins have been especially well characterized in developing rat and mouse skeletal muscles. MyHC-emb and MyHC-neo transcripts have been detected by in situ hybridization in the early developmental stages: in the mouse embryo, MyHC-emb is first detected at 9.5 days post coitum (E9.5) and MyHCneo at E10.5 [16]. The upregulation of these genes is apparently controlled by the activity of the myogenic regulatory factors MyoD and Myf5, involved in muscle commitment and differentiation, as the proximal promoters of developmental myosin genes contain E-boxes responding to MyoD and Myf5 [17, 18]. The developing skeletal muscles also express a myosin indistinguishable from the adult MyHC-slow, coded by $M Y H 7$, as determined by analyses at the protein and transcript level [19]. Based on the pattern of reactivity of a number of anti-myosin antibodies, it was suggested that the slowtype MyHC isoforms present in the embryonic muscles are actually different from those present in the adult skeletal muscle [20]; however, this interpretation has not been confirmed. It was also suggested that the slowtonic $\mathrm{MyHC}$, first identified in the extraocular muscles and intrafusal fibers of muscle spindles of the adult muscles [21] and recently found to be coded by the MYHTb gene [22], is a slow-developmental isoform widely expressed in most embryonic muscles [23]. However, $M Y H 7 b$ transcripts are present at very low levels in embryonic mouse muscle at E12, and MYH7b protein is not detected in embryonic and fetal muscle using a polyclonal antibody specific for the N-terminal domain of MYH7b, except for rare fibers, first identified around E20, destined to become the bag fibers of muscle spindles (see [22]). In conclusion, available evidence indicates that three MyHCs are present at the protein level in the developing rat and mouse skeletal muscle: MyHC-emb (MYH3), MyHC-neo (MYH8), and MyHCslow (MYH7). Immunohistochemical studies showed that the pattern of expression of developmental myosins varies in fibers formed at different developmental stages. In rat primary generation fibers, $\mathrm{MyHC}-\mathrm{emb}$ is coexpressed with MyHC-slow [19, 24], whereas secondary generation fibers express embryonic and neonatal
MyHCs [25]. At the later fetal stages, a number of primary generation fibers tend to lose $\mathrm{MyHC}$-slow and acquire MyHC-neo reactivity, while a number of secondary generation fibers in slow muscles stain also for MyHC-slow [25].

$\mathrm{MyHC}$ gene activation during embryonic myogenesis is accompanied by parallel upregulation of MLCs and other contractile protein genes. In situ hybridization studies showed that the transcripts for MLC-1emb (MYL4) are expressed together with MLC-1fast (the major splicing product of the MYL1 gene) beginning in the early developmental stages in the mouse embryonic skeletal muscle; their relative levels are similar at E12.5 but MLC-1fast becomes predominant at E15.5 [16]. MLC-2fast (MYL3) transcripts are also present early in mouse embryogenesis, with variable temporal and spatial patterns of expression in different muscle groups [26]. In contrast, transcripts for MLC-1slow/ventricular (MYL4) and MLC-3fast (another splicing product of the MYL1 gene) are not detectable in the developing muscles before E15 [16].

\section{Embryonic/neonatal-to-adult myosin switch}

Developmental myosins disappear in most skeletal muscles during the early postnatal development concomitantly with the upregulation of adult fast myosins. In the rat leg skeletal muscles, the transcripts for adult fast MyHCs (MyHC-2A, MyHC-2X, and MyHC-2B, coded by $M Y H 2, M Y H 1$, and $M Y H 4$, respectively) are first detected few days after birth by in situ hybridization and become predominant during the subsequent weeks [27]. This switch occurs earlier in the mouse skeletal muscles, as small amounts of adult fast myosin transcripts can be detected even before birth using sensitive RNAase protection assays and by in situ hybridization [28]. However, at the protein level, the fast newborn mouse muscles contain essentially MyHC-neo (about $70 \%$ ) and MyHCemb (about $30 \%$ ) with traces of MyHC-slow, as determined by high-resolution gel electrophoresis [29]. The timing of embryonic and neonatal myosin downregulation and adult fast myosin upregulation shows significant variation among body muscles, both at the mRNA [28] and protein level [29]. The elimination of developmental myosin may also vary within the same muscle, for example, neonatal myosin was found to persist longer in type $2 \mathrm{~A}$ fibers during postnatal development [30]. Interestingly, the timing of downregulation of developmental $\mathrm{MyHC}$ isoforms was essentially unchanged in MYH4 (2B) and MYH1 (2X) null mice [31].

The switch from developmental to adult fast MyHCs seen in rodent fast muscles takes place also in cultured muscle cells. It has been reported that $\mathrm{C} 2 \mathrm{C} 12$ muscle cells, when induced to differentiate upon transfer to low 
serum medium, first express MyHC-emb, MyHC-neo, and $\mathrm{MyHC}$-slow transcripts, starting at day 1 and peaking at day 2-4 then decreasing, whereas $\mathrm{MyHC}-2 \mathrm{~A}$, $\mathrm{MyHC}-2 \mathrm{X}$, and $\mathrm{MyHC}-2 \mathrm{~B}$ transcripts start to increase at day $2-4$ and peak by day 8 (the last time point examined) [32]. However, there are controversial results about the $\mathrm{MyHC}$ expression pattern in satellite cell cultures from different skeletal muscles (see [33, 34]), and masticatory-specific myosin heavy chain (Myh16) was detected in cultures of cat jaw muscle but not limb muscle, suggesting that muscle cells from jaw-closing muscles are preprogrammed to express these isoforms during myogenesis in vitro [35].

The developmental switch from developmental to adult MyHCs can be modulated by extrinsic hormonal and neural influences. The embryonic/neonatal-to-adult fast myosin switch is under the control of a thyroid hormone, hyperthyroidism inducing a precocious expression of adult fast myosin heavy chain mRNA and hypothyroidism inducing a delay in this switching [36-38]. In contrast, nerve activity is apparently not necessary for the embryonic/neonatal-to-fast myosin switch $[39,37]$ but is required to promote the postnatal accumulation of MyHC-slow and the disappearance of MyHC-emb in the slow soleus muscle [19].

The molecular mechanisms controlling the myosin switch during development remain to be established and probably involve specific regulatory sequences associated with the $M Y H$ gene cluster, where $M Y H$ genes are arranged in the order: $M Y H 3-M Y H 2-M Y H 1-M Y H 4-$ $M Y H 8-M Y H 13$. It has been reported that thyroid hormone controls the transition between neonatal and adult fast $2 \mathrm{~B}$ MyHC by a long non-coding antisense RNA which is transcriptionally regulated during postnatal development and in response to hypothyroidism: this antisense RNA is transcribed from a site within the intergenic region between $M Y H 8$ (MyHC-neo) and the closely associated $\mathrm{MYH4}$ (MyHC-2B) gene and appears to mediate the transcriptional repression of the $M Y H 8$ gene [40]. A central enhancer located between the MYH3 and MYH2 genes has been recently identified [41]. This enhancer, whose function is controlled by six homeoproteins, acts in cis by upregulating the expression of fast $M Y H$ genes (MYH2, MYH1, and MYH4), located downstream of the enhancer, and in trans via a long intergenic non-coding RNA (linc-Myh) to suppress the expression of MYH7 (MyHC-slow) [41]. However, it is not known whether this enhancer is also involved in the regulation of developmental myosin genes, $M Y H 3$ and $M Y H 8$, thus behaving like a $M Y H$ locus control region (LCR) similar to that present in the $\beta$ globin locus, or whether other LCRs, associated to the $M Y H$ gene cluster, control the developmental $M Y H$ switch.
Myosin changes in the developing human skeletal muscle The developmental pattern of myosin isoform expression in the human embryonic and fetal skeletal muscle has been comparatively less investigated. At week 8 of gestation, primary generation fibers with central nuclei are present in the human skeletal muscle, whereas secondary generation fibers are formed after week 10 and become the predominant fiber population by week 21 [42]. MyHC-emb, MyHC-slow, and MyHC-neo transcripts are detectable in the developing skeletal muscle at week 9 (Fig. 1). At the protein level, all primary myofibers express MyHC-emb and MyHC-slow [43, 44], with MyHC-emb being detectable before MyHC-slow in the initial myotubes [45]. The proportion of fibers staining for MyHC-slow decreases from $75 \%$ at week 10 to $3 \%$ at week 21 of gestation, due to the dramatic increase in secondary fibers that initially do not contain MyHCslow [45]. Secondary generation fibers express only MyHC-emb at week 12, MyHC-neo protein being detected at later stages [45]. Quantitative RNA analysis indicates that $M Y H 3$ transcripts account for about $81 \%$ of all $M Y H$ transcripts in the human fetal skeletal muscle at week 15 of gestation [46]. At week 16 to 17, a tertiary fiber population has been identified, initially composed of very small myofibers stained by an antimyosin antibody reactive with adult fast but not with neonatal MyHC [44, 47]. In situ hybridization indicates that MyHC-2A transcripts are weakly expressed at week 19 and more strongly at birth, whereas MyHC-2X transcripts are barely present at birth and are clearly expressed at 30 days after birth (Fig. 1). After week 27, a proportion of secondary fibers starts to express $\mathrm{MyHC}$ slow, and by week 30 , about $50 \%$ of all muscle fibers express MyHC-slow, like in adult muscle $[45,44]$. In the developing human muscles, both developmental MyHC isoforms are downregulated toward the end of gestation, the corresponding $\mathrm{MyHC}$ transcripts are expressed at low levels at birth, and in a 1-month-old infant, MyHCneo persists only in a few fibers [48] (Fig. 1). In conclusion, most human skeletal muscle fibers, probably more than $95 \%$, appear to derive from secondary and tertiary waves of myogenesis and their diversification into the fast type $2 \mathrm{~A}$ or slow type 1 lineage occurs before birth, during the third trimester of gestation, whereas the differentiation of type $2 \mathrm{X}$ fibers takes place in the first week after birth.

In the developing human quadriceps, three MLC proteins can be detected by 2D gel electrophoresis between week 7 and 12 [49]. MLC-3fast becomes clearly visible at week 25, when MLC-1emb starts to decrease rapidly. The major change during the third trimester of gestation is the progressive accumulation of the slow isoforms of MLC, so that at birth, the MLC profile is similar to that of adult muscle [49]. MLC-1sa transcripts are also 


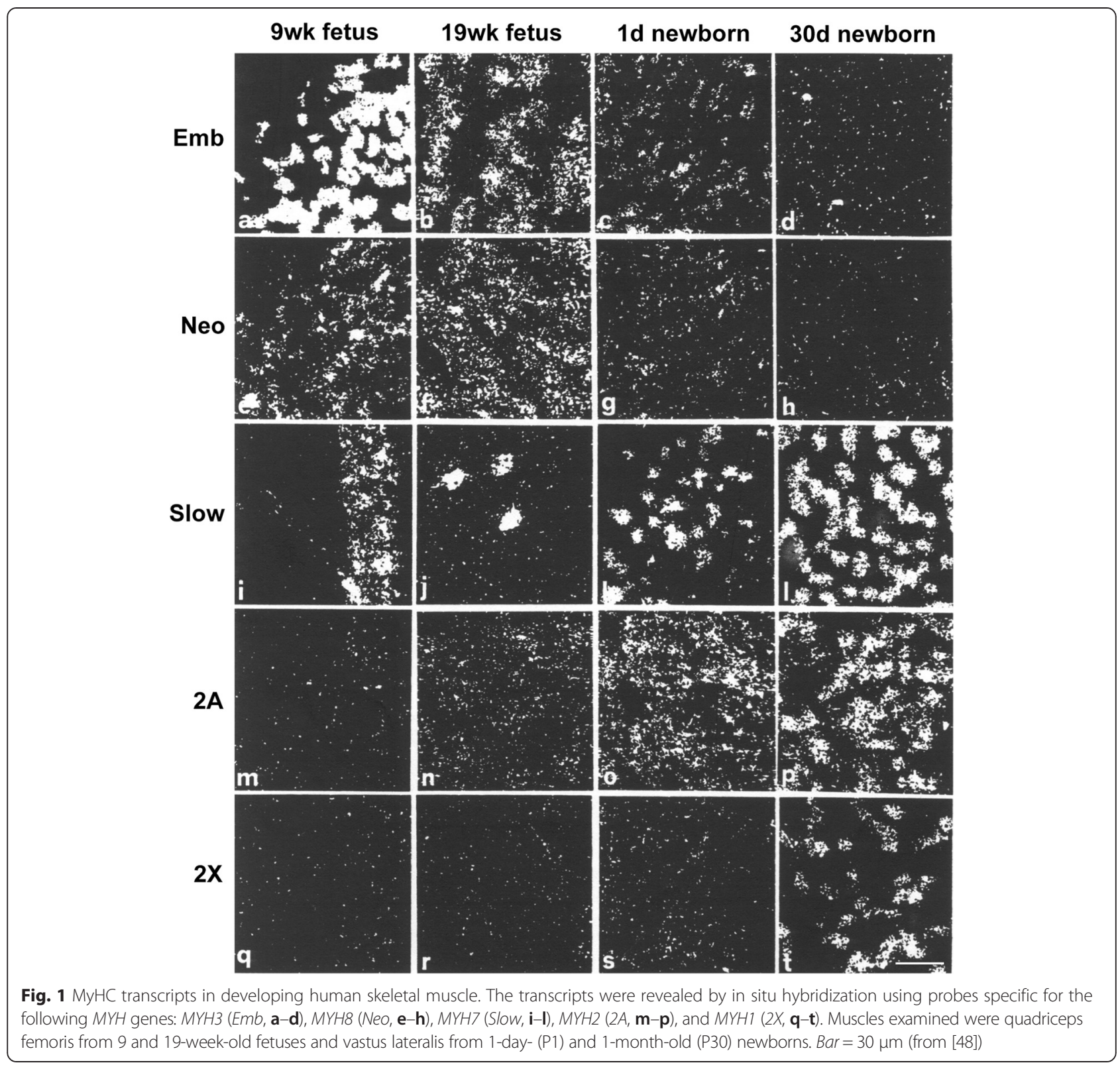

detectable in human skeletal muscles at week 24 , though at significantly lower levels compared to adult muscle [50].

\section{Developmental myosins in adult skeletal muscle}

Developmental MyHCs persist throughout adult stages in a number of fibers present in specialized muscles, including the extraocular muscles [51, 52] and muscle spindles $[53,54,23]$, as well as the jaw-closing muscles [55-57] and laryngeal muscles [58]. MLC-1emb/atrial is also present in adult human masseter muscle [55] and is the exclusive or predominant essential MLC associated with MyHC-M (MYH16) in the jaw-closing muscles of carnivores and other mammalian species $[59,60]$. A recent proteomics study of single fibers from the adult mouse skeletal muscle revealed that traces of MyHC-emb are detectable in all adult myofibers, whereas small amounts of MyHC-neo are present in fast muscle fibers [61]. MyHC-emb has also been detected in the adult human skeletal muscle [62]. In the extraocular muscles, the fibers expressing $\mathrm{MyHC}-\mathrm{emb}$ are specifically localized in the orbital layer (Fig. 2a) and show variations in expression along the length of the fibers, being more abundant in the distal zones and less abundant in the central zone (see [63]). In these muscles, embryonic myosin is usually co-expressed with 


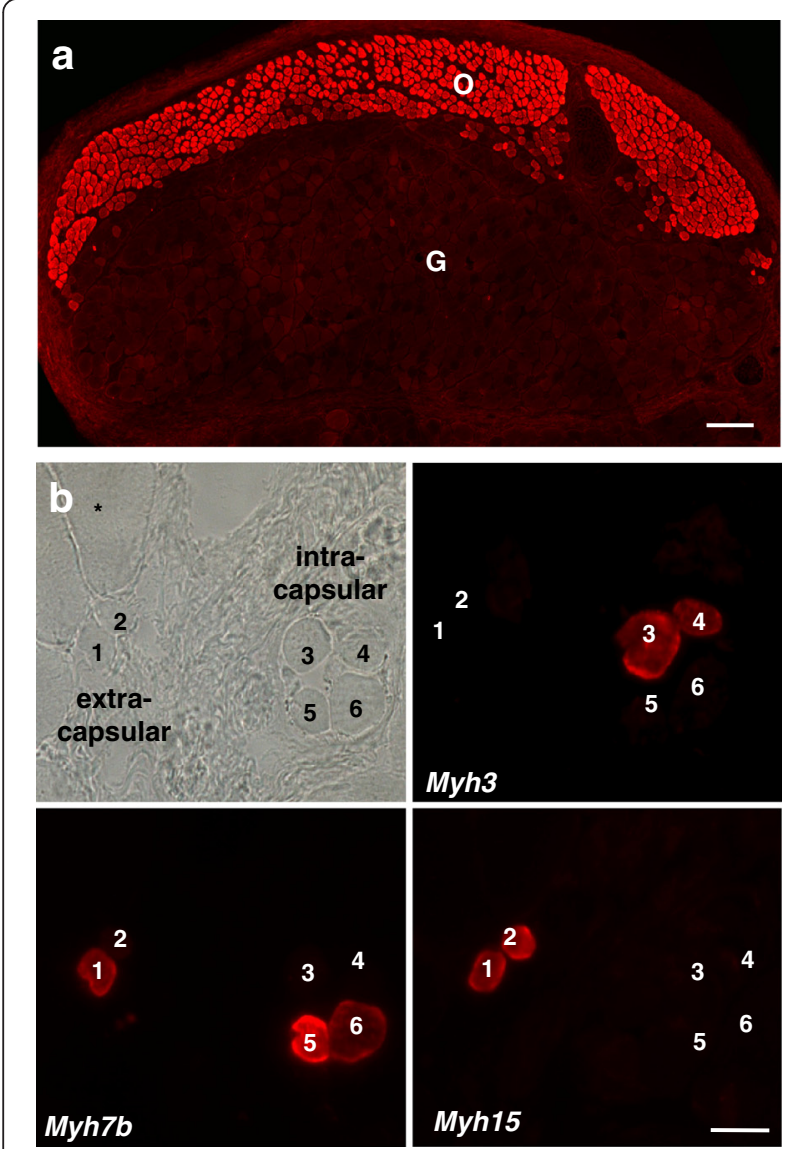

Fig. 2 Embryonic MyHC in adult skeletal muscles. a Transverse sections of rat extraocular muscle (rectus superior) reacted with a monoclonal antibody specific for MyHC-emb (BF-G6, see [76]). Note that embryonic myosin is expressed in most fibers of the orbital layer $(O)$ but only in rare fibers of the global layer $(G)$ of the muscle. Bar $=100 \mu \mathrm{m}$. b Embryonic myosin in intrafusal fibers of muscle spindles. Serial sections of rat soleus muscle viewed in phase contrast or stained for MyHC-emb (MYH3), MyHC-slow-tonic (MYH7b), or MYH15 (MYH15). Embryonic myosin is detected in the nuclear chain fibers of a muscle spindle ( 3 and 4 ) but not in the nuclear bag fibers (5 and 6), nor in the extracapsular region of an adjacent spindle (fibers 1 and 2). Extrafusal muscle fibers (asterisk) are unstained. Bar $=20 \mu \mathrm{m}$ (modified from [22])

other myosin types [63], including the newly discovered MYH15 [22]. In the two fiber types present in muscle spindles, the nuclear chain and nuclear bag fibers, MyHC-emb and MyHC-neo are mostly localized in nuclear chain fibers (Fig. 2b). The embryonic and neonatal $M Y H$ genes can be induced by hypothyroidism in specific adult muscles [64]. Muscle paralysis induced by resection of the nerve or by tetrodotoxin-induced block of nerve conduction also leads to re-expression of developmental myosins, which occurs specifically in type $2 \mathrm{~A}$ fibers but is generally restricted to short fiber segments [30].

\section{Re-expression of developmental myosins in regenerating} muscle

Skeletal muscles can efficiently regenerate after different types of injury (see [65] for a review). Muscle regeneration is mediated by the satellite cells present under the basal lamina of the muscle fibers, which are activated after injury and undergo proliferation and fusion, thus forming new muscle fibers. Regenerating muscle fibers re-express developmental isoforms of myosin, troponin, and other muscle proteins [66, 67, 3]. Embryonic and neonatal $\mathrm{MyHCs}$ are detected in newly formed regenerating myofibers at 2-3 days after injury and persist for 2-3 weeks (Fig. 3a). MLC-1emb is also transiently expressed in regenerating skeletal muscles [68]. Reexpression of developmental myosins can be revealed in a variety of conditions that involve muscle degeneration/ regeneration events, including injection of the snake
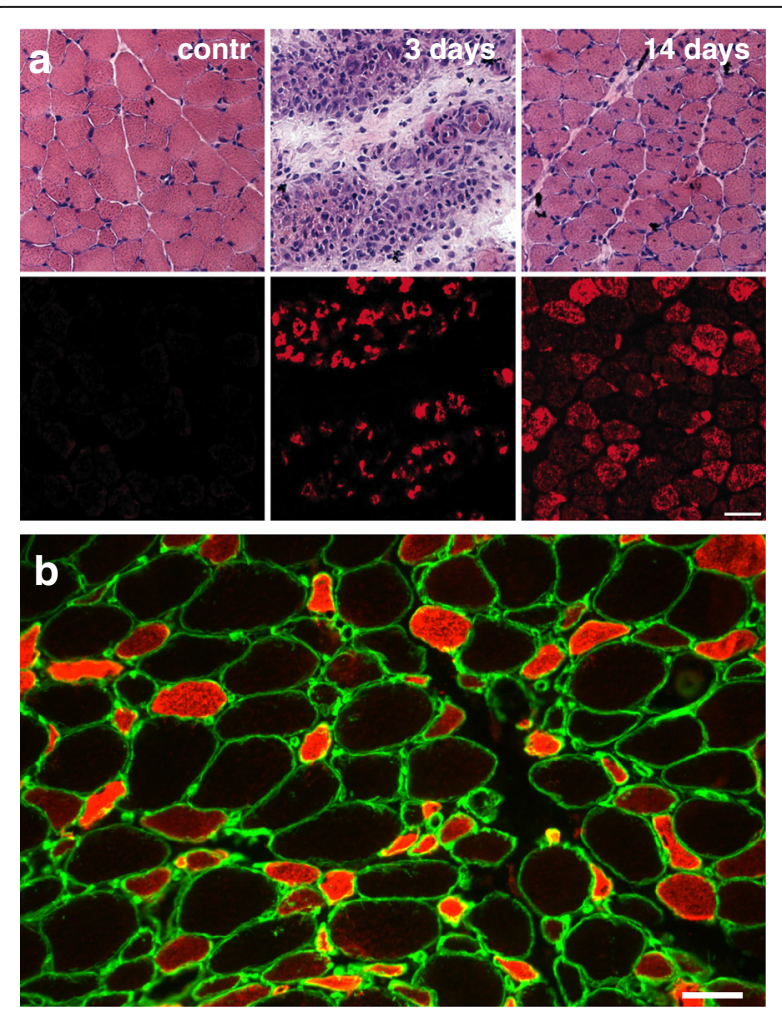

Fig. 3 Embryonic MyHC in regenerating muscle fibers. a Expression of embryonic myosin in regenerating rat skeletal muscle at various time periods after bupivacaine-induced injury. The progression of muscle regeneration from day 3 to day 14 after injury can be followed in serial sections stained with hematoxylin and eosin (upper panels) or immunostained for embryonic myosin (lower panels). Note the absence of embryonic myosin in the control muscle. Bar = $50 \mu \mathrm{m}$ (modified from [65]). b Regenerating muscle fibers staining for embryonic myosin in human myopathies. Section of human muscle biopsy from a patient with polymyositis stained for $\mathrm{MyHC}$-emb (red) and laminin (green). Note the large number of regenerating muscle fibers reactive for embryonic myosin. Bar $=50 \mu \mathrm{m}$ (courtesy of Elena Pegoraro) 
venoms notexin and cardiotoxin $[69,70]$, chronic denervation [71], or muscle damage induced by chronic electrical stimulation [72]. The presence of developmental myosins thus represents a useful marker of muscle regeneration in animal models of muscle disease, such as the dystrophin-deficient $m d x$ mouse model of muscular dystrophy [73] and in human myopathies, such as Duchenne muscular dystrophy [74] or polymyositis (Fig. $3 \mathrm{~b}$ ). The presence of embryonic myosin can also be a useful marker in the diagnosis of rhabdomyosarcoma $[75,76]$.

The switch from embryonic/neonatal-to-adult fast myosins in regenerating muscle is independent of innervation, whereas the switch to slow myosin is controlled by slow nerve activity $[69,66,70]$. In an extensively used model, with muscle injury induced by bupivacaine injection in the rat slow soleus muscle, regenerating myofibers express only embryonic and neonatal myosin transcripts at day 2-3 after injury but, at day 4 , start to express adult fast myosin mRNAs. However, in the presence of the nerve, the slow myosin is rapidly upregulated and fast myosin transcripts are downregulated, whereas in the absence of the nerve, adult fast myosins continue to accumulate and slow myosin transcripts remain undetectable [77]. This process is mediated by the pattern of nerve activity, as it can be reproduced by electrical stimulation of regenerating muscle using a stimulation pattern that mimics the endogenous slow motor neuron activity [78]. However, regenerating fast and slow muscles respond differently to the same stimulation pattern, supporting the possibility that the embryonic/neonatalto-adult fast or slow myosin switch reflects the existence of intrinsic differences between satellite cell populations in the various fiber types. This interpretation is consistent with a number of studies on cultured muscle cells; however, this issue is outside the scope of this review.

\section{Human congenital disorders due to mutations of embryonic and neonatal myosins}

The crucial role of embryonic and neonatal myosin during human development has more recently been demonstrated by the pathological consequences of $M Y H 3$ and MYH8 mutations (see [79]). Mutations in the MYH3 (MyHC-emb) gene are responsible for some types of distal arthrogryposis (DA) syndromes, congenital disorders characterized by multiple limb contractures [80]. MYH3 gene mutations have been associated with two major DA syndromes, DA2A and DA2B/DA1. Freeman-Sheldon syndrome (FSS, DA2A) is characterized by facial contractures and congenital scoliosis, in addition to contractures of the limbs. This is the most severe of the DA syndromes and patients require nutritional, surgical, and rehabilitative intervention [81]. FSS was also known as the "whistling-face syndrome", because the lips appear pursed or pinched leaving only a small oral opening. In fact, to date, the only identified cause of FSS is mutation in the MYH3 gene. DA2B (Sheldon-Hall syndrome, SHS) and DA1, which appear to represent the extremes of the same phenotypically variable and genetically heterogeneous condition, can also be due to $M Y H 3$ mutations [82]. However, DA2B and DA1 can also be caused by mutations in TNNI2, coding for fast troponin I, TNNT3, coding for fast troponin $\mathrm{T}$, and TPM2, coding for $\beta$-tropomyosin.

Most MYH3 mutations in DA2A and DA2B do not overlap, suggesting that there is a relationship between MYH3 genotype and phenotype (Fig. 4), and also within DA2A several aspects of the phenotype are associated with specific mutations [80]. Three MYH3 mutations involving conserved residues, T178I, R672H, and R672C, account for more than $90 \%$ of the $M Y H 3$ mutations that cause FSS, with T178I being the most severe and R672C the least [81]. However, T178I has also been associated with SHS. Both R672 and T178 residues map to a groove adjacent to the nucleotide binding site, suggesting that mutation of these residues may alter the active site surrounding the nucleotide binding site. In contrast, residues mutated in SHS generally localize to surfaces that may interact with other proteins of the contractile apparatus such as actin and troponin: this could explain why a similar SHS phenotype can be caused by TNNI2 and TNNT3 mutations (Fig. 4).

MYH8 (MyHC-neo) mutations are responsible for another form of distal arthrogryposis (DA7), referred to as the trismus-pseudocamptodactyly syndrome (TPS) because the patients cannot open the mouth fully (trismus) and show an unusual camptodactyly (flexion of the fingers) that is evident only on dorsiflexion of the wrist (i.e., pseudocamptodactyly). In contrast to the large number of MYH3 mutations causing FSS and SHS, only a single MYH8 mutation (R674Q) has been identified in different families with trismus-pseudocamptodactyly syndrome $[83,84]$. The affected residue R674, which because of different numbering corresponds to R672 in the MYH3 gene described above, is conserved in different vertebrate species and in different $M Y H$ gene coding for sarcomeric myosins. This residue is localized near the ATP binding site and may thus interfere with myosin catalytic activity. In the family described by Veugelers et al. [84], TPS was found to be associated with manifestations typical of the Carney complex, including the presence of cardiac myxomas, suggesting a possible role of the MYH8 gene in cardiac development. However, this association was not found in the families reported by Toydemir et al. [83], and TPS was never observed in large collections of Carney complex cases [85].

How can one explain the congenital contractures induced by mutations in developmental myosins? A 


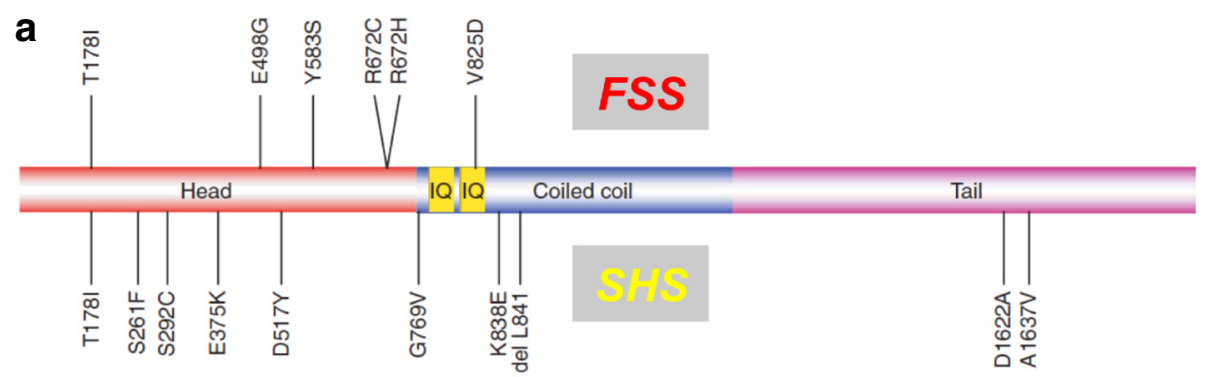

b

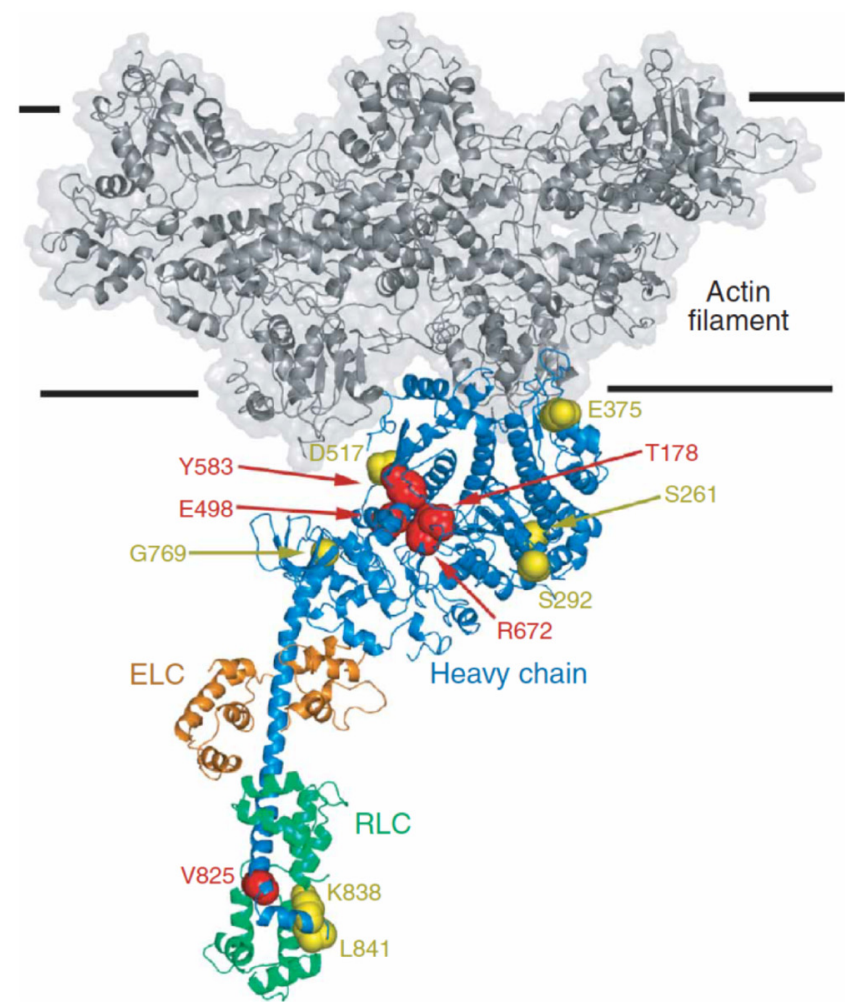

Fig. 4 MYH3 mutations causing distal arthrogryposis. a Scheme of the embryonic myosin molecule showing the sites of different mutations causing Freeman-Sheldon syndrome (FSS, above) and Sheldon-Hall syndrome (SHS, below). Note that most mutations localize to the head domain of the myosin molecule, and that mutations causing FSS differ from those causing SHS. b A model of the actin-myosin complex. A portion of the actin filament comprising five actin monomers is shown as a dark gray ribbon. Myosin heavy chain (Heavy chain), essential light chain (ELC), and regulatory light chain $(R L C)$ are shown as blue, orange, and green ribbons, respectively. MYH3 mutations causing distal arthrogryposis are shown with oversized space-filling atoms, with FSS mutations colored red and SHS mutations yellow (modified from [80])

plausible interpretation is that $M Y H 3$ or $M Y H 8$ gene mutations interfere with myosin's catalytic activity due to the dominant negative effect of the mutated allele, thus causing defects in myofiber force production in utero. Active movements of the embryo are required for the normal development of the joints, as shown by classic studies in the chick embryo [86, 87]. These studies showed that muscle paralysis induced in ovo by neuromuscular blocking agents, such as curare or botulinum toxin, causes arthrogryposis. The orofacial dysmorphisms induced by $M Y H 3$ or $M Y H 8$ gene mutations might reflect a similar role of the contraction of facial expression muscles in shaping the form of the face during fetal development.

The view that mutations of $M Y H 3$ and $M Y H 8$ lead to hypocontractility of fetal muscles has received support by two recent findings. First, the alteration of the crossbridge turnover in patients carrying $\mathrm{R} 672 \mathrm{C}$ mutation has been confirmed by a detailed analysis of myofibril and single-fiber mechanics [62]. Second, preliminary results with isolated myosin S1 (subfragment 1), the portion of the myosin molecule comprising the myosin head and lever arm, which is sufficient to drive actin sliding movement in in vitro motility assays, have shown that several 
kinetic parameters of the cross-bridge cycle are altered in the presence of $\mathrm{R} 672 \mathrm{C}, \mathrm{R} 672 \mathrm{H}$, and T178I FSS-causing mutations [88].

\section{Contractile properties of embryonic and neonatal myosins}

Pioneering studies in the 1960s showed that a transition in contractile properties occurs around or just after birth in cat $[89,90]$ and rat muscles $([91,92]$, see [93] for a review), as depicted in Fig. 5a, b. During the first week of postnatal development, isometric force increases in both slow and fast muscles, while maximum shortening velocity increases in fast but not in slow muscles. The increase in strength could be explained by addition of myofibrils in parallel (but see below); however, the change in maximum shortening velocity points to changes in myosin isoforms, which are assumed to be the major determinants of maximum shortening velocity and ATPase activity [94]. Further support to this interpretation was given by the observation of a parallel increase in myosin ATPase activity during development [92], whereas the acceleration in rate of tension rise and the reduction of twitch time parameters presumably reflect a convergent contribution of changes in myosin kinetics and maturation of sarcoplasmic reticulum $[92,95]$.

The changes due to myosin isoform developmental replacement were studied in rabbit psoas single fibers [96]. At birth, neonatal myosin is predominant and is progressively replaced by adult fast isoforms. The link
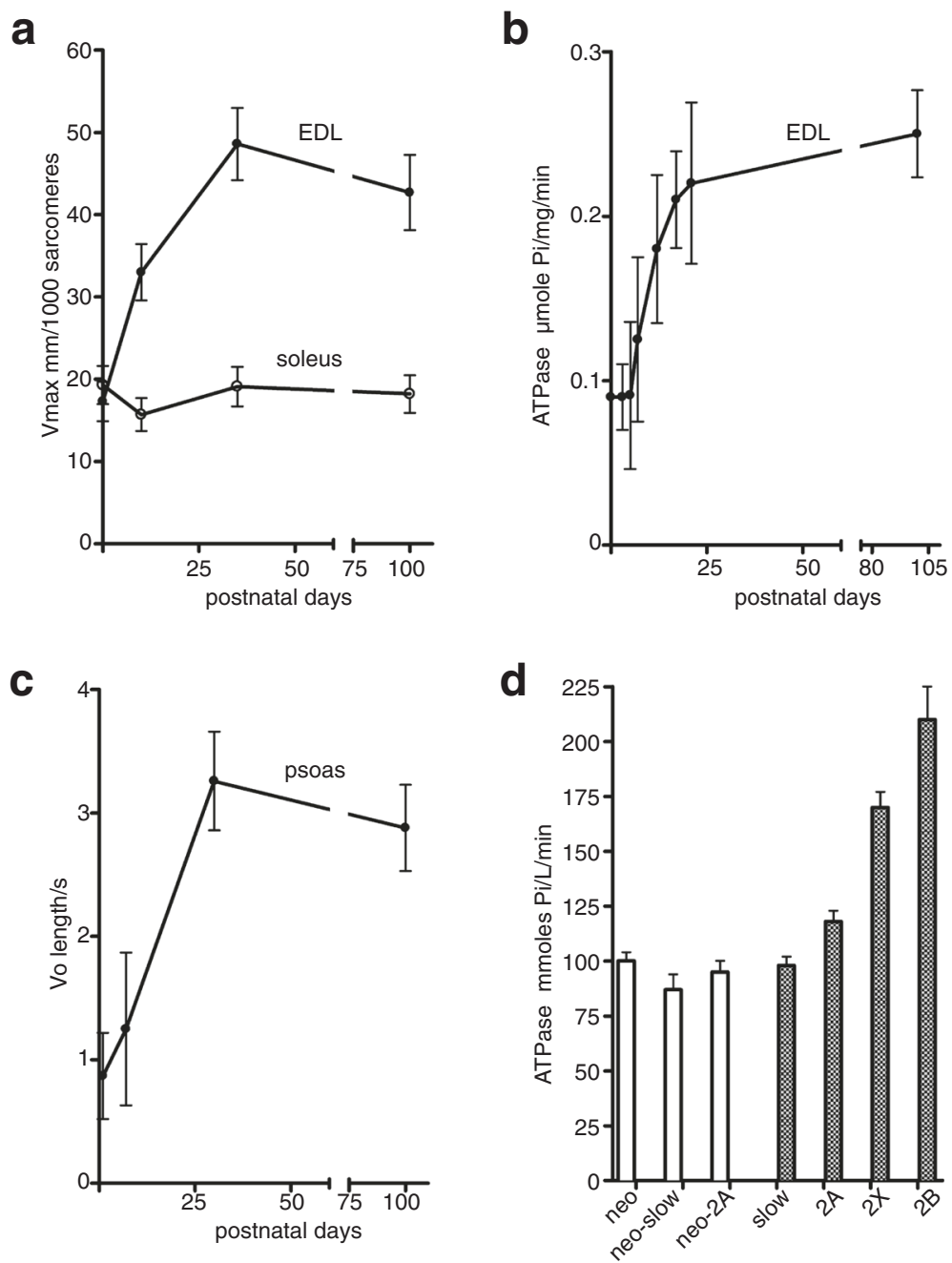

Fig. 5 Kinetic properties of neonatal myosin. a, b Postnatal changes in maximum shortening velocity (a) and ATPase activity (b) in rat extensor digitorum longus (EDL) muscle. Note that the developmental replacement of neonatal myosin with adult fast myosin during the first week after birth is accompanied by a twofold increase in $V_{\max }$ and ATPase activity. (Panel a redrawn from Table 1 of [91], panel $\mathbf{b}$ redrawn from Figure 3 (a) of [92]). c Unloaded shortening velocity of single fibers of rabbit psoas increases during postnatal stages concomitantly with the replacement of neonatal with adult fast isoforms (redrawn from data in text and in Figure 2 of [96]). $\mathbf{d}$ Myofibrillar ATPase activity of single fibers isolated from neonatal and adult rat diaphragm muscle and identified in relation to their MyHC isoform composition. Note the lower ATPase activity of neonatal compared to adult fast fibers (redrawn from data in Figure 4 of [98]) 
between myosin isoform replacement and changes in contractile properties, maximum shortening velocity, and ATPase activity has been analyzed in single muscle fibers where $\mathrm{MyHC}$ expression was determined by gel electrophoresis. In rabbit psoas, replacement of neonatal MyHC with adult fast, mainly $2 \mathrm{X}$, isoforms is associated with a threefold increase in maximum shortening velocity [96] (see Fig. 5c). In the rat diaphragm, neonatal myosin is the predominant isoform in the first two weeks after birth, although rarely expressed alone in individual fibers, but more often associated with fast 2A myosin [97-99]. Fibers expressing predominantly neonatal myosin show values of shortening velocity and ATPase activity comparable to slow fibers and much lower than fast $2 \mathrm{X}$ and $2 \mathrm{~B}$ fibers (Fig. 5d). The disappearance of neonatal myosin is associated with an increase in ATP consumption rate [98] and increase in power output [99].

The view that, in mammals, neonatal myosin has kinetics similar to $2 \mathrm{~A}$ myosin but slower than $2 \mathrm{X}$ and $2 \mathrm{~B}$ myosins has received support from the experiments on recombinant human myosin S1 motor domain expressed in C2C12 myotubes [100]. An additional interesting feature emerging from Resnicow et al. [100] data is that $K_{m}$ values for actin are much greater for developmental than for adult myosins. This suggests even lower values of ATP hydrolysis rate for immature myofibrils in conditions other than maximal actin activation.

The functional features of embryonic myosin are still little known. The study by Resnicow et al., however, shows that the kinetics of embryonic myosin are slower than those of neonatal myosin, both for ATPase rate and for actin filament sliding velocity [100]. Although the interpretation of this result is complicated by the finding that embryonic myosin motor domain did not bind any light chain when expressed in $\mathrm{C} 2 \mathrm{C} 12$ myogenic cells, an independent study points to the same conclusion [46]. Purified myosin and intact myofibrils were prepared from human muscle samples obtained from four fetuses of the age of 12-15 weeks post conception. Quantitative PCR and protein analysis showed that MyHC-emb was largely predominant, above $80 \%$ of the total myosin present. Compared to psoas rabbit myosin (likely a mixture of $2 \mathrm{X}$ and $2 \mathrm{~B}$ myosins), the actin filament velocity of the human embryonic myosin was more than three times lower. Taking into account that rabbit myosins are approximately two times as fast as human embryonic muscle $\operatorname{myosin}(\mathrm{s})$ [101], one can assume that gliding speed of actin filaments on human embryonic myosin is at least 1.5 times lower than on fast human myosin.

Intact myofibrils also allowed determination of force and rate of force development and decline. Force developed by myofibrils containing embryonic myosin was found to be more than ten times lower than that developed by adult human myofibrils [46]. No data are available for the ability to develop force of myofibril containing neonatal myosin, but the results obtained on embryonic myosin suggest that the increase of active force during development may be due not only to accumulation of myofibrils in parallel but also to the transition of myosin isoforms.

While the kinetic properties of the contractile response are almost exclusively linked to the MyHC isoforms, the force development might also be significantly affected by other proteins present in the myofibrillar apparatus. Developmental changes in MLC gene expression (see above) may be relevant. In the thin filament, embryonic and neonatal skeletal muscle may also express unique isoforms: for example, cardiac troponin $\mathrm{T}$ $(\mathrm{TnT})$ is expressed in embryonic skeletal muscle and unique TnT isoforms, presumably derived by alternative splicing of the fast skeletal muscle TnT gene, are detected in fetal and neonatal muscle [67].

\section{Functional significance of developmental myosins}

One relevant question remains unanswered: what is the advantage (or necessity), if any, of having specific myosin isoforms during muscle development. Two distinct interpretations can be considered. One possibility is that developmental myosins have structural characteristics appropriate for myofibril formation during myogenesis, both in the embryo and during muscle regeneration in the adult. According to the premyofibril model of myofibrillogenesis developed by Sanger from studies in avian cardiac and skeletal muscle cells and recently confirmed in mouse skeletal muscle cells [102], myofibril assembly in premyofibrils is characterized by bands of class II non-muscle myosin alternating along actin fibers with bands of muscle-specific $\alpha$-actinin. The transition from the premyofibril to the nascent myofibril is marked by the addition of class II muscle (sarcomeric) myosin, but it is not known whether the presence at this stage of $\mathrm{MyHC}$-emb is an obligatory step for myofibrillogenesis to occur in skeletal muscle cells. Knockout experiments in vivo or knockdown experiments in cultured muscle cells would be required to address this question. It should be stressed that myofibrils essentially identical to those present in skeletal muscle are formed in the absence of $\mathrm{MyHC}$-emb in developing cardiac muscle cells, which contain only MyHC- $\beta$ /slow and MyHC- $\alpha$ [103]. Knockout or knockdown experiments could also be used to determine whether embryonic and neonatal isoforms have redundant functions, so that one of them is able to fully compensate for the lack of the other.

Another possibility is that embryonic and neonatal myosins have unique properties adapted to the prenatal developmental environment. For example, it is well known that fetal hemoglobin has a greater oxygen 
affinity than adult hemoglobin due to specific embryonic and fetal globins, whose presence contributes to transplacental oxygen flux in the context of a relative hypoxic intrauterine environment [104]. Developmental switching of contractile proteins might also be affected by oxygen tension. In cardiac muscle, hypoxia was shown to reactivate gene expression programs of early cardiac development, with upregulation of MyHC-slow (MYH7) and downregulation of MyHC- $\alpha$ cardiac (MYH6), both in ventricles from rats exposed to hypobaric hypoxia and in neonatal rat cardiomyocytes incubated in a hypoxic chamber [105]. In cultured skeletal muscle cells, hypoxia was found to stimulate the expression of $\mathrm{MyHC}$-slow via HIF-1 $\alpha$ [106]. The developmental switching of troponin I from the slow skeletal to the cardiac isoform, that is known to modulate the calcium sensitivity of the contractile apparatus, has been associated with the greater resistance to hypoxia and acidosis of the fetal and neonatal heart (see [107]). However, to our knowledge, there is no comparative study on the effect of hypoxia and acidosis on the function of developmental and adult myosins in skeletal muscle. The low ATPase rate typical of neonatal, and even more, embryonic myosin might suggest that these myosin isoforms allow a contractile activity at a very low energetic cost.

An alternative possibility is that load-bearing properties of developmental myosins play an important role in the transitions of myosin during development, as fetal muscles contract against a very low load compared to postnatal muscles [108]. It is tempting to speculate that fetal tendons, joints, and bones require the mechanical stimuli produced by muscle contraction for their correct growth but, at the same time, cannot bear excessive strains, and embryonic myosin might have appropriate properties in this respect. Accordingly, it has been speculated that the persistence of developmental myosins in the extraocular muscles may be related to the fact that oculorotatory muscles contract against a much lower load compared to other skeletal muscles [51]. This interpretation could be tested by specific experimental approaches. In particular, it will be crucial to determine the contractility of embryonic and neonatal myosin by loaded in vitro motility assays and single-molecule analyses with a dual-beam laser trap (see [109]).

\section{Conclusions}

The presence of unique MyHCs and MLCs in developing skeletal muscle and their re-expression in regenerating muscle was first reported in the late 1970s to early 1980s. During the subsequent years, the gene coding for embryonic and neonatal myosins were characterized, their expression patterns were defined, and the factors involved in the developmental-to-adult myosin switch were identified. However, the physiological significance of developmental myosins remained completely unclear until 2006, when embryonic (MYH3) mutations were first reported to cause specific syndromes characterized by congenital joint contractures. This finding has opened up a new phase of research aimed at dissecting the functional properties of embryonic and neonatal myosins and the consequences of their mutations. Analyses on myofibrils and single fibers, and especially on isolated myosin S1, are expected to define the kinetic parameters of the cross-bridge cycle of developmental myosins and their response to loading conditions, thus addressing the unsettled question of why specific myosin isoforms are needed during muscle development.

\section{Abbreviations}

DA: distal arthrogryposis; FSS: Freeman-Sheldon syndrome; MLC: myosin light chain (protein); MYH: myosin heavy chain (gene); MyHC: myosin heavy chain (protein); MYL: myosin light chain (gene); SHS: Sheldon-Hall syndrome; TPS: trismus-pseudocamptodactyly syndrome.

\section{Competing interests}

The authors declare that they have no competing interests.

\section{Authors' contributions}

SS conceived and wrote the review. ACR and VS provided figures and gave substantial contribution to the data collection. CR wrote the part on physiology, including contractile properties of normal and mutant myosins. LAL revised critically the manuscript. All authors read and approved the final manuscript.

\section{Acknowledgements}

We thank Prof. Elena Pegoraro for providing the polymyositis biopsy and Irene Moretti and Stefano Ciciliot for the help with the figures.

\section{Author details}

${ }^{1}$ Venetian Institute of Molecular Medicine (VIMM), Via G. Orus 2, 35129 Padova, Italy. ${ }^{2}$ Department of Molecular, Cellular and Developmental Biology and BioFrontiers Institute, University of Colorado, Boulder, CO, USA. ${ }^{3}$ Institute of Anatomy, Faculty of Medicine, University of Ljubljana, Ljubljana, Slovenia. ${ }^{4}$ Department of Biomedical Sciences, University of Padova, Padova, Italy. ${ }^{5} \mathrm{CNR}$ Institute of Neuroscience, Padova, Italy.

Received: 30 March 2015 Accepted: 27 May 2015

Published online: 15 July 2015

\section{References}

1. Schiaffino S, Reggiani C. Fiber types in mammalian skeletal muscles. Physiol Rev. 2011;91:1447-531.

2. Whalen RG, Sell SM, Butler-Browne GS, Schwartz K, Bouveret $P$, Pinset-Harstom I. Three myosin heavy-chain isozymes appear sequentially in rat muscle development. Nature. 1981;292:805-9.

3. Sartore S, Gorza L, Schiaffino S. Fetal myosin heavy chains in regenerating muscle. Nature. 1982;298:294-6.

4. Periasamy M, Wieczorek DF, Nadal-Ginard B. Characterization of a developmentally regulated perinatal myosin heavy-chain gene expressed in skeletal muscle. J Biol Chem. 1984;259:13573-8.

5. Wydro RM, Nguyen HT, Gubits RM, Nadal-Ginard B. Characterization of sarcomeric myosin heavy chain genes. J Biol Chem. 1983;258:670-8.

6. Leinwand LA, Saez L, McNally E, Nadal-Ginard B. Isolation and characterization of human myosin heavy chain genes. Proc Natl Acad Sci U S A. 1983;80:3716-20.

7. Weiss A, Schiaffino S, Leinwand LA. Comparative sequence analysis of the complete human sarcomeric myosin heavy chain family: implications for functional diversity. J Mol Biol. 1999;290:61-75.

8. Kurabayashi M, Komuro I, Tsuchimochi H, Takaku F, Yazaki Y. Molecular cloning and characterization of human atrial and ventricular myosin alkali light chain cDNA clones. J Biol Chem. 1988;263:13930-6. 
9. Whalen RG, Butler-Browne GS, Gros F. Identification of a novel form of myosin light chain present in embryonic muscle tissue and cultured muscle cells. J Mol Biol. 1978;126:415-31.

10. Ikeda D, Ono Y, Snell P, Edwards YJ, Elgar G, Watabe S. Divergent evolution of the myosin heavy chain gene family in fish and tetrapods: evidence from comparative genomic analysis. Physiol Genomics. 2007;32:1-15.

11. Elworthy S, Hargrave M, Knight R, Mebus K, Ingham PW. Expression of multiple slow myosin heavy chain genes reveals a diversity of zebrafish slow twitch muscle fibres with differing requirements for Hedgehog and Prdm1 activity. Development. 2008;135:2115-26.

12. Nord H, Burguiere AC, Muck J, Nord C, Ahlgren U, von Hofsten J. Differential regulation of myosin heavy chains defines new muscle domains in zebrafish. Mol Biol Cell. 2014;25:1384-95.

13. Bandman E, Rosser BW. Evolutionary significance of myosin heavy chain heterogeneity in birds. Microsc Res Tech. 2000;50:473-91.

14. Sacks LD, Cann GM, Nikovits Jr W, Conlon S, Espinoza NR, Stockdale FE. Regulation of myosin expression during myotome formation. Development. 2003;130:3391-402

15. Stockdale FE. Myogenic cell lineages. Dev Biol. 1992;154:284-98.

16. Lyons GE, Ontell M, Cox R, Sassoon D, Buckingham M. The expression of myosin genes in developing skeletal muscle in the mouse embryo. J Cell Biol. 1990;111:1465-76.

17. Beylkin DH, Allen DL, Leinwand LA. MyoD, Myf5, and the calcineurin pathway activate the developmental myosin heavy chain genes. Dev Biol. 2006;294:541-53.

18. Konig S, Burkman J, Fitzgerald J, Mitchell M, Su L, Stedman H. Modular organization of phylogenetically conserved domains controlling developmental regulation of the human skeletal myosin heavy chain gene family. J Biol Chem. 2002;277:27593-605.

19. Narusawa M, Fitzsimons RB, Izumo S, Nadal-Ginard B, Rubinstein NA Kelly AM. Slow myosin in developing rat skeletal muscle. J Cell Biol. 1987:104:447-59.

20. Hughes SM, Cho M, Karsch-Mizrachi I, Travis M, Silberstein L, Leinwand LA, et al. Three slow myosin heavy chains sequentially expressed in developing mammalian skeletal muscle. Dev Biol. 1993;158:183-99.

21. Bormioli SP, Sartore S, Vitadello M, Schiaffino S. "Slow" myosins in vertebrate skeletal muscle. An immunofluorescence study. J Cell Biol. 1980;85:672-81.

22. Rossi AC, Mammucari C, Argentini C, Reggiani C, Schiaffino S. Two novel/ ancient myosins in mammalian skeletal muscles: MYH14/7b and MYH15 are expressed in extraocular muscles and muscle spindles. J Physiol. 2010;588:353-64

23. Walro JM, Kucera J. Why adult mammalian intrafusal and extrafusal fibers contain different myosin heavy-chain isoforms. Trends Neurosci. 1999:22:180-4

24. Rubinstein NA, Kelly AM. Development of muscle fiber specialization in the rat hindlimb. J Cell Biol. 1981;90:128-44.

25. Condon K, Silberstein L, Blau HM, Thompson WJ. Development of muscle fiber types in the prenatal rat hindlimb. Dev Biol. 1990;138:256-74.

26. Faerman $\mathrm{A}$, Shani $\mathrm{M}$. The expression of the regulatory myosin light chain 2 gene during mouse embryogenesis. Development. 1993;118:919-29.

27. DeNardi C, Ausoni S, Moretti P, Gorza L, Velleca M, Buckingham M, et al. Type 2X-myosin heavy chain is coded by a muscle fiber type-specific and developmentally regulated gene. J Cell Biol. 1993;123:823-35.

28. Lu BD, Allen DL, Leinwand LA, Lyons GE. Spatial and temporal changes in myosin heavy chain gene expression in skeletal muscle development. Dev Biol. 1999;216:312-26.

29. Agbulut O, Noirez P, Beaumont F, Butler-Browne G. Myosin heavy chain isoforms in postnatal muscle development of mice. Biol Cell. 2003;95:399-406.

30. Schiaffino S, Gorza L, Pitton G, Saggin L, Ausoni S, Sartore S, et al. Embryonic and neonatal myosin heavy chain in denervated and paralyzed rat skeletal muscle. Dev Biol. 1988;127:1-11.

31. Allen DL, Leinwand LA. Postnatal myosin heavy chain isoform expression in normal mice and mice null for Ilb or Ild myosin heavy chains. Dev Biol. 2001;229:383-95.

32. Brown DM, Parr T, Brameld JM. Myosin heavy chain mRNA isoforms are expressed in two distinct cohorts during C2C12 myogenesis. J Muscle Res Cell Motil. 2012:32:383-90.

33. LaFramboise WA, Guthrie RD, Scalise D, Elborne V, Bombach KL, Armanious CS, et al. Effect of muscle origin and phenotype on satellite cell muscle-specific gene expression. J Mol Cell Cardiol. 2003;35:1307-18.
34. Zhu H, Park S, Scheffler JM, Kuang S, Grant AL, Gerrard DE. Porcine satellite cells are restricted to a phenotype resembling their muscle origin. J Anim Sci. 2013;91:4684-91

35. Kang LH, Rughani A, Walker ML, Bestak R, Hoh JF. Expression of masticatoryspecific isoforms of myosin heavy-chain, myosin-binding protein- $C$ and tropomyosin in muscle fibers and satellite cell cultures of cat masticatory muscle. J Histochem Cytochem. 2010;58:623-34.

36. Butler-Browne GS, Herlicoviez D, Whalen RG. Effects of hypothyroidism on myosin isozyme transitions in developing rat muscle. FEBS Lett. 1984;166:71-5.

37. Gambke B, Lyons GE, Haselgrove J, Kelly AM, Rubinstein NA. Thyroidal and neural control of myosin transitions during development of rat fast and slow muscles. FEBS Lett. 1983;156:335-9.

38. Russell SD, Cambon N, Nadal-Ginard B, Whalen RG. Thyroid hormone induces a nerve-independent precocious expression of fast myosin heavy chain mRNA in rat hindlimb skeletal muscle. J Biol Chem. 1988;263:6370-4.

39. Butler-Browne GS, Bugaisky LB, Cuenoud S, Schwartz K, Whalen RG. Denervation of newborn rat muscle does not block the appearance of adult fast myosin heavy chain. Nature. 1982;299:830-3.

40. Pandorf CE, Jiang W, Qin AX, Bodell PW, Baldwin KM, Haddad F. Regulation of an antisense RNA with the transition of neonatal to Ilb myosin heavy chain during postnatal development and hypothyroidism in rat skeletal muscle. Am J Physiol Regul Integr Comp Physiol. 2012;302:R854-67.

41. Sakakibara I, Santolini M, Ferry A, Hakim V, Maire P. Six homeoproteins and a linc-RNA at the fast MYH locus lock fast myofiber terminal phenotype. PLoS Genet. 2014;10:e1004386.

42. Fidzianska A. Human ontogenesis. I. Ultrastructural characteristics of developing human muscle. J Neuropathol Exp Neurol. 1980;39:476-86.

43. Barbet JP, Thornell LE, Butler-Browne GS. Immunocytochemical characterisation of two generations of fibers during the development of the human quadriceps muscle. Mech Dev. 1991;35:3-11.

44. Draeger A, Weeds AG, Fitzsimons RB. Primary, secondary and tertiary myotubes in developing skeletal muscle: a new approach to the analysis of human myogenesis. J Neurol Sci. 1987;81:19-43.

45. Cho M, Webster SG, Blau HM. Evidence for myoblast-extrinsic regulation of slow myosin heavy chain expression during muscle fiber formation in embryonic development. J Cell Biol. 1993;121:795-810.

46. Racca AW, Beck AE, Rao VS, Flint GV, Lundy SD, Born DE, et al. Contractility and kinetics of human fetal and human adult skeletal muscle. J Physiol. 2013;591:3049-61.

47. Ecob-Prince M, Hill M, Brown W. Immunocytochemical demonstration of myosin heavy chain expression in human muscle. J Neurol Sci. 1989;91:71-8.

48. Smerdu V. Expression of myosin heavy chain transcripts within distinct types of human muscle fibres. Slovenia: University of Ljubljana; 2002.

49. Butler-Browne GS, Barbet JP, Thornell LE. Myosin heavy and light chain expression during human skeletal muscle development and precocious muscle maturation induced by thyroid hormone. Anat Embryol (Berl). 1990;181:513-22.

50. Hailstones DL, Gunning PW. Characterization of human myosin light chain 1 sa and 3nm: implications for isoform evolution and function. Mol Cell Biol. 1990:10:1095-104.

51. Sartore S, Mascarello F, Rowlerson A, Gorza L, Ausoni S, Vianello M, et al. Fibre types in extraocular muscles: a new myosin isoform in the fast fibres. J Muscle Res Cell Motil. 1987;8:161-72.

52. Wieczorek DF, Periasamy M, Butler-Browne GS, Whalen RG, Nadal-Ginard B. Co-expression of multiple myosin heavy chain genes, in addition to a tissue-specific one, in extraocular musculature. J Cell Biol. 1985;101:618-29.

53. Eriksson PO, Butler-Browne GS, Thornell LE. Immunohistochemical characterization of human masseter muscle spindles. Muscle Nerve. 1994;17:31-41.

54. Rowlerson A, Gorza L, Schiaffino S. Immunohistochemical identification of spindle fiber types in mammalian muscle using type-specific antibodies to isoforms of myosin. In: The Muscle Spindle. London: Macmillan; 1985.

55. Butler-Browne GS, Eriksson PO, Laurent C, Thornell LE. Adult human masseter muscle fibers express myosin isozymes characteristic of development. Muscle Nerve. 1988:11:610-20.

56. d'Albis A, Janmot C, Bechet JJ. Comparison of myosins from the masseter muscle of adult rat, mouse and guinea-pig. Persistence of neonatal-type isoforms in the murine muscle. Eur J Biochem. 1986;156:291-6.

57. Stal P, Eriksson PO, Schiaffino S, Butler-Browne GS, Thornell LE. Differences in myosin composition between human oro-facial, masticatory and limb 
muscles: enzyme-, immunohisto- and biochemical studies. J Muscle Res Cell Motil. 1994;15:517-34.

58. Toniolo L, Maccatrozzo L, Patruno M, Caliaro F, Mascarello F, Reggiani C. Expression of eight distinct $\mathrm{MHC}$ isoforms in bovine striated muscles: evidence for MHC-2B presence only in extraocular muscles. J Exp Biol. 2005;208:4243-53.

59. Reiser PJ, Bicer S, Chen Q, Zhu L, Quan N. Masticatory (;superfast') myosin heavy chain and embryonic/atrial myosin light chain 1 in rodent jaw-closing muscles. J Exp Biol. 2009;212:2511-9.

60. Reiser PJ, Bicer S, Patel R, An Y, Chen Q, Quan N. The myosin light chain 1 isoform associated with masticatory myosin heavy chain in mammals and reptiles is embryonic/atrial MLC1. J Exp Biol. 2010;213:1633-42.

61. Murgia M, Nagaraj N, Deshmukh AS, Zeiler M, Cancellara P, Moretti I, et al. Single muscle fiber proteomics reveals unexpected mitochondrial specialization. EMBO Rep. 2015;16(3):387-95.

62. Racca AW, Beck AE, McMillin MJ, Korte FS, Bamshad MJ, Regnier M. The embryonic myosin R672C mutation that underlies Freeman-Sheldon syndrome impairs cross-bridge detachment and cycling in adult skeletal muscle. Hum Mol Genet. 2015;24(12):3348-58.

63. Zhou Y, Liu D, Kaminski HJ. Myosin heavy chain expression in mouse extraocular muscle: more complex than expected. Invest Ophthalmol Vis Sci. 2010;51:6355-63.

64. Izumo S, Nadal-Ginard B, Mahdavi V. All members of the MHC multigene family respond to thyroid hormone in a highly tissue-specific manner. Science. 1986;231:597-600

65. Ciciliot S, Schiaffino S. Regeneration of mammalian skeletal muscle. Basic mechanisms and clinical implications. Curr Pharm Des. 2010;16:906-14.

66. Esser K, Gunning P, Hardeman E. Nerve-dependent and -independent patterns of mRNA expression in regenerating skeletal muscle. Dev Biol. 1993;159:173-83.

67. Saggin L, Gorza L, Ausoni S, Schiaffino S. Cardiac troponin T in developing, regenerating and denervated rat skeletal muscle. Development. 1990;110:547-54

68. Carraro U, Dalla Libera L, Catani C. Myosin light and heavy chains in muscle regenerating in absence of the nerve: transient appearance of the embryonic light chain. Exp Neurol. 1983;79:106-17.

69. d'Albis A, Couteaux R, Janmot C, Roulet A, Mira JC. Regeneration after cardiotoxin injury of innervated and denervated slow and fast muscles of mammals. Myosin isoform analysis. Eur J Biochem. 1988;174:103-10.

70. Whalen RG, Harris JB, Butler-Browne GS, Sesodia S. Expression of myosin isoforms during notexin-induced regeneration of rat soleus muscles. Dev Biol. 1990;141:24-40

71. Carraro U, Morale D, Mussini I, Lucke S, Cantini M, Betto R, et al. Chronic denervation of rat hemidiaphragm: maintenance of fiber heterogeneity with associated increasing uniformity of myosin isoforms. J Cell Biol. 1985;100:161-74

72. Maier A, Gorza L, Schiaffino S, Pette D. A combined histochemical and immunohistochemical study on the dynamics of fast-to-slow fiber transformation in chronically stimulated rabbit muscle. Cell Tissue Res. 1988;254:59-68.

73. DiMario JX, Uzman A, Strohman RC. Fiber regeneration is not persistent in dystrophic (MDX) mouse skeletal muscle. Dev Biol. 1991;148:314-21.

74. Schiaffino S, Gorza L, Dones I, Cornelio F, Sartore S. Fetal myosin immunoreactivity in human dystrophic muscle. Muscle Nerve. 1986:9:51-8.

75. Eusebi V, Rilke F, Ceccarelli C, Fedeli F, Schiaffino S, Bussolati G. Fetal heavy chain skeletal myosin. An oncofetal antigen expressed by rhabdomyosarcoma. Am J Surg Pathol. 1986;10:680-6.

76. Schiaffino S, Gorza L, Sartore S, Saggin L, Carli M. Embryonic myosin heavy chain as a differentiation marker of developing human skeletal muscle and rhabdomyosarcoma. A monoclonal antibody study. Exp Cell Res. 1986;163:211-20

77. Jerkovic R, Argentini C, Serrano-Sanchez A, Cordonnier C, Schiaffino S. Early myosin switching induced by nerve activity in regenerating slow skeletal muscle. Cell Struct Funct. 1997;22:147-53.

78. Kalhovde JM, Jerkovic R, Sefland I, Cordonnier C, Calabria E, Schiaffino S, et al. "Fast" and "slow" muscle fibres in hindlimb muscles of adult rats regenerate from intrinsically different satellite cells. J Physiol. 2005;562:847-57.

79. Tajsharghi H, Oldfors A. Myosinopathies: pathology and mechanisms. Acta Neuropathol. 2013;125:3-18
80. Toydemir RM, Rutherford A, Whitby FG, Jorde LB, Carey JC, Bamshad MJ. Mutations in embryonic myosin heavy chain (MYH3) cause Freeman-Sheldon syndrome and Sheldon-Hall syndrome. Nat Genet. 2006:38:561-5.

81. Beck AE, McMillin MJ, Gildersleeve HI, Shively KM, Tang A, Bamshad MJ. Genotype-phenotype relationships in Freeman-Sheldon syndrome. Am J Med Genet A. 2014;164A:2808-13.

82. Beck AE, McMillin MJ, Gildersleeve HI, Kezele PR, Shively KM, Carey JC, et al. Spectrum of mutations that cause distal arthrogryposis types 1 and $2 B$. Am J Med Genet A. 2013;161A:550-5.

83. Toydemir RM, Chen H, Proud VK, Martin R, van Bokhoven H, Hamel BC, et al. Trismus-pseudocamptodactyly syndrome is caused by recurrent mutation of MYH8. Am J Med Genet A. 2006;140:2387-93.

84. Veugelers M, Bressan M, McDermott DA, Weremowicz S, Morton CC, Mabry CC, et al. Mutation of perinatal myosin heavy chain associated with a Carney complex variant. N Engl J Med. 2004;351:460-9.

85. Stratakis CA, Bertherat J, Carney JA. Mutation of perinatal myosin heavy chain. N Engl J Med. 2004;351:2556-8. author reply -8.

86. Drachman DB, Sokoloff $L$. The role of movement in embryonic joint development. Dev Biol. 1966;14:401-20.

87. Murray PD, Drachman DB. The role of movement in the development of joints and related structures: the head and neck in the chick embryo. J Embryol Exp Morphol. 1969;22:349-71.

88. Velazquez CV, Walklate J, Deacon J, Geeves MA, Leinwand LA. Functional analysis of Freeman-Sheldon syndrome causing mutations on embryonic myosin. Biophys J. 2015;108:304a.

89. Buller AJ, Eccles JC, Eccles RM. Differentiation of fast and slow muscles in the cat hind limb. J Physiol. 1960;150:399-416.

90. Buller AJ, Lewis DM. Further observations on the differentiation of skeletal muscles in the kitten hind limb. J Physiol. 1965;176:355-70.

91. Close R. Dynamic properties of fast and slow skeletal muscles of the rat during development. J Physiol. 1964;173:74-95.

92. Drachman DB, Johnston DM. Development of a mammalian fast muscle: dynamic and biochemical properties correlated. J Physiol. 1973;234:29-42.

93. Close Rl. Dynamic properties of mammalian skeletal muscles. Physiol Rev. 1972;52:129-97.

94. Schiaffino S, Reggiani C. Molecular diversity of myofibrillar proteins: gene regulation and functional significance. Physiol Rev. 1996;76:371-423.

95. Luff AR, Atwood HL. Changes in the sarcoplasmic reticulum and transverse tubular system of fast and slow skeletal muscles of the mouse during postnatal development. J Cell Biol. 1971:51:369-83.

96. Reiser PJ, Moss RL, Giulian GG, Greaser ML. Shortening velocity and myosin heavy chains of developing rabbit muscle fibers. J Biol Chem. 1985:260:14403-5.

97. Geiger PC, Bailey JP, Mantilla CB, Zhan WZ, Sieck GC. Mechanisms underlying myosin heavy chain expression during development of the rat diaphragm muscle. J Appl Physiol (1985). 2006;101:1546-55

98. Sieck GC, Prakash YS, Han YS, Fang YH, Geiger PC, Zhan WZ. Changes in actomyosin ATP consumption rate in rat diaphragm muscle fibers during postnatal development. J Appl Physiol (1985). 2003;94:1896-902.

99. Zhan WZ, Watchko JF, Prakash YS, Sieck GC. Isotonic contractile and fatigue properties of developing rat diaphragm muscle. J Appl Physiol (1985). 1998;84:1260-8.

100. Resnicow DI, Deacon JC, Warrick HM, Spudich JA, Leinwand LA. Functional diversity among a family of human skeletal muscle myosin motors. Proc Natl Acad Sci U S A. 2010;107:1053-8.

101. Pellegrino MA, Canepari M, Rossi R, D'Antona G, Reggiani C, Bottinelli R. Orthologous myosin isoforms and scaling of shortening velocity with body size in mouse, rat, rabbit and human muscles. J Physiol. 2003;546:677-89.

102. White J, Barro MV, Makarenkova HP, Sanger JW, Sanger JM. Localization of sarcomeric proteins during myofibril assembly in cultured mouse primary skeletal myotubes. Anat Rec (Hoboken). 2014;297:1571-84.

103. Lyons GE, Schiaffino S, Sassoon D, Barton P, Buckingham M. Developmental regulation of myosin gene expression in mouse cardiac muscle. J Cell Biol. 1990;111:2427-36

104. Brittain T. Molecular aspects of embryonic hemoglobin function. Mo Aspects Med. 2002;23:293-342.

105. Razeghi P, Essop MF, Huss JM, Abbasi S, Manga N, Taegtmeyer $H$. Hypoxia-induced switches of myosin heavy chain iso-gene expression in rat heart. Biochem Biophys Res Commun. 2003;303:1024-7. 
106. Slot IG, Schols AM, Vosse BA, Kelders MC, Gosker HR. Hypoxia differentially regulates muscle oxidative fiber type and metabolism in a HIF-1alpha-dependent manner. Cell Signal. 2014;26:1837-45.

107. Schiaffino S, Gorza L, Ausoni S. Troponin isoform switching in the developing heart and its functional consequences. Trends Cardiovasc Med. 1993;3:12-7.

108. Caplan Al, Fiszman MY, Eppenberger HM. Molecular and cell isoforms during development. Science. 1983;221:921-7.

109. Spudich JA. Hypertrophic and dilated cardiomyopathy: four decades of basic research on muscle lead to potential therapeutic approaches to these devastating genetic diseases. Biophys J. 2014;106:1236-49.

\section{Submit your next manuscript to BioMed Central} and take full advantage of:

- Convenient online submission

- Thorough peer review

- No space constraints or color figure charges

- Immediate publication on acceptance

- Inclusion in PubMed, CAS, Scopus and Google Scholar

- Research which is freely available for redistribution 